\section{Kư KAstamonu Eğitim Dergisi Kastamonu Education Journal}

Temmuz 2019 Cilt:27 Sayı:4

kefdergi.kastamonu.edu.tr
Başvuru Tarihi/Received: 23.10.2018

Kabul Tarihi/Accepted: 13.02.2019

DOI: $10.24106 /$ kefdergi.3008

\title{
Ortaokul Öğretmenlerinin Algılarına Göre Okul Etkililiği ile Kolaylaştırıcı Okul Yapısı ve Akademik İyimserlik Arasındaki ílişki'
}

\section{The Relationship Between School Effectiveness and Enabling School Structure and Academic Optimism According to the Middle School Teachers Perceptions}

\section{Öz}

\author{
Temel ÇALIK², Nagihan TEPE
}

Bu araştırmanın amacı ortaokul öğretmenlerinin kolaylaştırıcı okul yapısı, akademik iyimserlik ve okul etkililiği algıları arasındaki ilişkileri inceleyerek, öğretmenlerin kolaylaştırıcı okul yapısı ve akademik iyimserlik algılarının okul etkililiği algıları üzerindeki yordayıcılık etkisini belirlemektir. Katılımcılar; 589'u kadın ve 562'si erkek olmak üzere 1151 ortaokul öğretmeninden oluşmaktadır. Araştırma ilişkisel tarama modelinin kullanıldığı nicel bir araştırmadır. Araştırma sonuçlarına göre öğretmenlerin okul yapısı, akademik iyimserlik ve okul etkililiği düzeyleri arasında pozitif yönlü ve anlamlı ilişkiler tespit edilmiştir. Ayıca öğretmenlerin okul yapısı ve akademik iyimserlik algılarının, okul etkililiği algıları üzerinde anlamlı yordayıcılar olduğu sonucuna ulaşılıştır.

Anahtar Kelimeler: Okul etkililiği, kolaylaştırıcı okul yapısı, akademik iyimserlik, öğretmen.

\section{Abstract}

Aim of this study is to examine the relationship of the middle school teachers' enabling school structure, academic optimis and school effectiviness perceptions and also explores the predictive influence of the middle school teachers' enabling school structure and academic optimism on perceptions of their school effectiviness. Participants consisted of 1151 middle school teachers including 589 females and 562 males. The research is a quantitative study using correlational screening model. The results of the research showed that there are positive and significant relationships between the teachers' school structure, academic optimism and school effectiveness. Also, school structure and academic optimism are significant predictors of school effectiveness.

Keywords: School effectiveness, enabling school structure, academic optimism, teacher

1. Bu çalışma Nagihan TEPE tarafindan Gazi Üniversitesi "Eğitim Yönetimi ve Denetimi”" Doktora Programı kapsamında Prof. Dr. Temel ÇALIK danışmanlığında hazırlanan doktora tezinden türetilmistir.

2. Gazi Üniversitesi, Eğitim Fak., Eğitim Bilimleri Bölümü, Ankara, Türkiye, https://orcid.org/0000-0003-3656-6260

3. Samsun Üniversitesi, Iiktisadi, İdari ve Sosyal Bilimler Fak., Iletişim Tasarımı ve Yönetimi Bölümü, Samsun, Türkiye, https://orcid.org/0000-0002-5923-435X Atıf / Citation: Çalık, T., \& Tepe, N. (2019). Ortaokul öğretmenlerinin algılarına göre okul etkililiği ile kolaylaştıııı okul yapısı ve akademik iyimserlik arasındaki ilişki. Kastamonu Education Journal, 27(4), xxx-xxx. doi:10.24106/kefdergi.3008 


\section{Extended Abstract}

It is important for school-building activities to make schools, students and teachers happier, success improved, educational goals reached, individual and community productivity and learning organizations provided peace of mind. In this context, the evaluation of school performance according to student success and teacher perceptions is called school effectiveness (Tarter \& Hoy, 2004, s. 541). The key concept to make schools better and effective is the school structure; this building is called the enabling school structure and is an integral part of designing better schools, with the qualities that enable employees to be creative, work together and do their jobs professionally and develop them (Hoy \& Sweetland, 2001, p. 319). In addition to contributing to enabling schools in the dimension of the structure that makes the organization effective, it is also possible to examine the dimension of individuals and behavior in other dimensions under the frame of academic optimism. Academic optimism categorized in terms of cognitive, behavioral, and emotional dimensions are examined as cognitive domain collective competence, affective domain school trust, and behavioral domain as academic emphasis (Fahy, Wu \& Hoy, 2010; Hoy, Tarter \& Hoy, 2006; Wu, Hoy \& Tarter, 2013).

Aim of this study is to examine the relationship of the middle school teachers' enabling school structure, academic optimis and school effectiviness perceptions and also explores the predictive influence of the middle school teachers' enabling school structure and academic optimism on perceptions of their school effectiviness.

Participants consisted of 1151 middle school teachers including 589 females and 562 males. The research is a quantitative study using correlational screening model. A total of 3 scales including school effectiveness scale, academic optimism scale and school structure scale were used in the research. Explanatory factor analysis and confirmatory factor analysis were performed by the researcher for the validity and reliability studies of the scales. The Pearson Moments Multiplication Correlation Coefficient was caluculated to determine the inter-variable relationships, and Multiple Linear Regression analysis was conducted to examine predictive variables.

According to the results of the research, there were positive and significant relationships between the teachers' school structure, academic optimism and school effectiveness. In addition, it was found that the highest relationship was between the enabling school structure, which is the sub-dimension of the school structure, and the school effectiveness, and the lowest relationship was between the coercive school structure, which is the sub-dimension of the school structure, and the trust, which is the sub-dimension of academic optimism. Research findings show that school structure and academic optimism are significant predictors of school effectiveness. In addition, the enabling school structure which is the the subscale of the school structure, and the academic self-efficacy and academic emphasis which are the subscales of academic optimism, were found to be significant predictors of school effectiveness; but it has been found that the coercive school structure which is the sub-dimension of the school structure and trust, which is the sub-dimension of academic optimism, are not significant predictors of school effectiveness. Furthermore, research findings show that self-efficacy, academic emphasis, and the enabling school structure were significant predictors in the subscales of school effectiveness, flexibility, education, and adaptability; but coercive school structure and trust are not significant predictors in all three dimensions.

Findings of this study are consistent with some previous research findings in the related literature. As a result of the research done, it was concluded that there is a positive relationship between facilitating school structure and academic optimism (Messick, 2002). While Adams (2003) concluded that facilitating school structure was important in improving teacher self-efficacy, Rhoads (2009) concluded that there is a positive relationship between facilitating school structure and teacher self-efficacy and significant relationships. Tracy (2009) found that school structure was associated with school effectiveness, and Anderson (2012) found significant relationships between facilitating school structure and academic optimism. Özdemir and Kılınç (2014) concluded that there is a positive and meaningful relationship between the effective bureaucratic school structure and the academic optimism levels of the teachers. In addition to these studies, it was concluded that there is a positive and significant relationship between bureaucratic school structure and teacher self-efficacy (Kılınç, Koşar, Er \& Öğdem, 2016). On the other hand the findings of this study seem to be inconsistent with some previous research results in the related literature. For example, according to Guldan (2004) 's work on facilitating bureaucracy, school trust and self-efficacy, there is no significant relationship between facilitating school structure and self-efficacy. 


\section{Giriş}

Okulları, öğrenci ve öğretmenlerin daha mutlu olduğu, başarının arttı̆̆ı, eğitimin belirlenen hedeflerine ulaşıldığı, bireysel ve toplumsal verimlilik ile huzurun sağlandığı öğrenen örgütler haline getirebilmek için okul geliştirme faaliyetlerine yönelik yapılan çalışmaların önemi büyüktür. Bu bağlamda okul performansının öğrenci başarısına ve öğretmen algılarına göre değerlendirilmesi ise okul etkililiği olarak adlandırılmaktadır (Tarter \& Hoy, 2004, s. 541).

Coleman Raporu olarak bilinen, 1966 yılında gerçekleştirilen ve etkili okullarla ilgili ilk çalışma sayılabilecek araştırmada okulların çocuğun yaşantısında, aile ve sosyal çevreye göre daha az rol oynadığı ifade edilse de (Gökçe \& Kahraman, 2010, s.175), Coleman'ın bulgularından farklı olarak çeşitli araştırmacılar (Dorman, Lipsitz \& Verner, 1985; Elmore, 1992; Edmonds, 1979; Fouts, 2002; Hoy \& Hannum, 1997; Mortimore \& Sammons'tan aktaran Brice, 1992; Zigarelli, 1966) okulun öğrenci başarısında önemli rol oynadığını savunmuşlardır.

Okulların daha iyi ve etkili olması için gerekli olan anahtar kavram okul yapısı olup; çalışanların daha yaratıcı, iş birliği içinde ve işlerini profesyonelce yapmasını sağlayan, onları geliştiren nitelikler taşıyan bu yapı kolaylaştırıcı okul yapısı olarak adlandırılır ve daha iyi okullar tasarlamanın ayrılmaz bir parçasını oluşturur (Hoy \& Sweetland, 2001, s. 319). Örgütlerin özellikle de okulların, rekabetçi ve başarılı olarak yirmi birinci yüzyılın intiyacı olacak şekilde etkili olabilmeleri için kolaylaştırıcı yapılara sahip olmaları gerekmektedir (Hoy \& Sweetland, 2000, s. 529).

Okullardaki bürokratik yapıyı incelemenin önemini Anderson (1974) şu şekilde ifade etmiştir (akt. Sinden, Hoy \& Sweetland, 2004; s. 462): Yapı müdahale edilebilir bir değişken olduğundan, doğru anlaşıldığı zaman öğretmen ve öğrencilere en iyi şekilde hizmet etmek için tasarlanabilir. íkincisi, örgütsel araştrrmalarda okul konusunda duyulan ilginin giderek artmasının, eğitimin paydaşları olan birey ve grupları okulları daha etkili hale getirmek için söz sahibi olmayı talep etmesidir. Son olarak okulların varoluş amaçlarından birinin öğrenci başarısını sağlamak olduğu göz önünde bulundurulduğunda, bu amacı gerçekleştirmek için daha iyi koşulların nasıl sağlanabileceğini araştıran çalışmaların önem taşıdığı vurgulanabilir.

Okulların da diğer örgütler gibi bürokrasi ile işlediklerini savunan Hoy ve Sweetland (2001, s.300), bürokratik okul yapılarının olumlu ve olumsuz yönlerini inceleyerek okul bürokrasinin gelişmesini sağlayan iki zıt görüş belirtmişlerdir (Messick, 2012, s. 15). Kolaylaştırıcı ve zorlaştırıcı okul yapısı şeklinde gerçekleştirilen bu sınıflandırmada, kolaylaştırıcı okul yapısını benimseyen okullarda; yardımlaşma ve yenilikçilik vurgulanır, kurallara sıkı sıkıya bağılıktan ziyade esneklik vardır, problemler firsat olarak görülerek çözümü kolaylaştrılır, okulu iyileştirme ve geliştirme için iş birliği teşvik edilir. Zorlaştırıcı ya da diğer bir adıyla engelleyici yapıyı benimseyen okullarda ise kurallara sıkı sıkıya bağılık vardır esneklik yoktur, yenilikçilik teşvik edilmez, ast üst arasında sıkı bir disiplin vardır, problemler engel olarak görülür, güvensizlik ortamı hakimdir (Hoy ve Sweetland, 2001; Sinden vd., 2004).

Okulları etkili hale getirmede örgütü oluşturan yapı boyutunda kolaylaştırıcı yapının katkısı yanında, diğer boyutlar olan birey ve davranış boyutunu da akademik iyimserlik çatısı altında incelemek mümkündür. Bilişsel, davranışsal ve duyuşsal boyutlar açısından sınıflandıılan akademik iyimserlik, bilişsel alanda kolektif yeterlik, duyuşsal alanda okul güveni ve davranışsal alanda ise akademik vurgu şeklinde incelenmektedir (Fahy, Wu \& Hoy, 2010; Hoy, Tarter \& Hoy, 2006; Wu, Hoy \& Tarter, 2013).

Akademik vurgu boyutu; bir okulda öğrenmeye odaklanılması ve bu amaçla belirli davranışların gerçekleştirilmesine yönelik baskıyı, kolektif yeterlik; öğretmende öğrencinin öğrenmesini geliştirmeye yönelik gösterdiği çabaların olumlu bir etkiye sahip olacağına dair algıyı (Beard, Hoy \& Woolfolk Hoy, 2010, s. 3), güven ise; bir grubun karşı tarafin yardımsever, güvenilir, dürüst, açık, yetkin olduğuna inanarak ona karşı savunmasız kalmaya istekli olması şeklinde ifade edilmektedir (Hoy \& Tschannen-Moran, 1999; s. 189).

Akademik vurgu, kolektif yeterlik ve güven okulların karakteristik özellikleri olup, sosyo ekonomik seviye ve okul düzeyi değişkenleri kontrol edildiğinde öğrenci başarısı ile ilişkili olduğu görülmüştür. İncelenen araştırmalarda bu üç değişkenin okulun normatif ve davranışsal ortamını şekillendirdiği belirlenmiştir (Smith \& Hoy, 2007, s. 559). Akademik iyimserlik öğrencilerin öğrenmesini kolaylaştırmak, okulların nasıl en iyi olacağını açıklamak ve geliştirmek için uğraşır (Smith \& Hoy, 2007, s. 566).

Literatürde okul etkililiği ile okul kültürü (Ayık \& Ada, 2009), kolektif yeterlik (Cooper, 2010), örgütsel vatandaşlık (Cooper, 2010), iş doyumu (Dodson, 2005), liderlik (Brice, 1992), okul geliştirme (Turner, 2002), öğrenci başarısı (Lassiter, 1994), sosyal uyum (Lassiter, 1994) ve öğretimsel liderlik (Buzzi, 1990) gibi çeşitli boyutların incelendiği çalışmaların mevcut olduğu görülmektedir. Okul yapısı ve diğer örgütsel boyutlar arasında yapılan çalışmalar incelendiğinde ise; akademik iyimserlik (McGuigan, 2005; Messick, 2012; Özdemir \& Kılınç, 2014), liderlik stilleri (Buluç, 2009), öğretmen 
profesyonelizmi (Cerit, 2012), farkındalık (Marshall, 2013; Watts, 2009), kolektif yeterlik (Adams, 2003; Rhoads, 2009), örgütsel vatandaşlık davranışı (Messick, 2012), okul iklimi (Jacob, 2003; Mayerson, 2010), okul etkililiği (Mayerson, 2010), güven (Adams, 2003), akademik gelişme (McGuigan, 2005), öğretmen güçlendirme (Watts, 2009), örgütsel sessizlik ve örgütsel sinizm (Demirtaş, Özdemir \& Küçük, 2016) gibi araştırmaların mevcut olduğu görülmektedir. Akademik iyimserlik ile ilgili yapılan çalışmalar incelendiğinde ise; örgütsel bağlılık (Çağlar, 2013; Çoban \& Demirtaş, 2011), değişim (Çağlar, 2014), okul iklimi (Kılınç, 2013), öz yeterlik (Sezgin \& Erdoğan, 2015), başarı algısı (Sezgin \& Erdoğan, 2015), değerler (Uzun, 2014), okul kültürü (Yılmaz \& Kurşun, 2015), mesleki tükenmişlik (Yalçın, 2013), öğrenci başarısı (Anderson, 2012; Bevel, 2010; Boonen, Pinxten, Damme \& Onghena, 2014; Chang, 2011; Hoy vd., 2006; Smith \& Hoy, 2007; Wu, 2012), dağıtımcı liderlik (Chang, 2011; Malloy, 2012), kolaylaştırıcı okul yapısı (Anderson, 2012; McGuigan, 2005; Messick, 2012; Wu, Hoy \& Tarter, 2013), kolektif sorumluluk (Wu, 2012; Wu vd. 2013), dönüşümcü liderlik (Rutledge II, 2010), örgütsel iklim (Reeves, 2010), okul etkililiği (Reeves, 2010; ikbal, 2016) ve örgütsel vatandaşlık (Messick, 2012) gibi boyutlarla akademik iyimserlik arasındaki ilişkinin ele alındığı çalışmaların olduğu görülmektedir.

Literatürde yapılan yukarıdaki çalışmalar incelendiğinde okul başarısında temel kavramlar olan okul etkililiği, akademik iyimserlik ve kolaylaştııı yapı kavramlarından herhangi biri ile örgütsel davranışın alt boyutlarını içeren liderlik, örgüt kültürü, örgüt iklimi, değişim, iletişim, örgütsel vatandaşlık, örgütsel bağlıık gibi kavramlar arasındaki ilişkilerin ele alındığı görülmektedir. Okul etkililiği, kolaylaştırıcı okul yapısı ve akademik iyimserlik kavramlarının bir arada ele alınarak daha büyük ve derinlemesine bir analizin ortaya koyulduğu yerli veya yabancı herhangi bir çalışma olmaması bu alanda bir eksiklik olarak görülerek bu çalışmanın çıkış noktasını oluşturmuş, bu genel çerçeve içerisinde, okulları oluşturan yapı, birey ve davranış unsurları altında etkili okulların ele alınması amaçlanmıştr. Araştırmanın çat kavramı olarak ise okul etkililiği kavramı belirlenmiş olup, bu çatının ayaklarını oluşturan kavramlar yapı boyutunda kolaylaştırıcı okul yapısı, birey ve davranış boyutunda ise akademik iyimserlik kavramları olarak incelenecek, ayrıca okul etkililiği üzerindeki yordayıcılıkları incelenecektir.

Araştırmanın alt amaçları:

- Ortaokul öğretmenlerinin kolaylaştırıcı okul yapısı, akademik iyimserlik ve okul etkililiği algıları arasında anlamlı bir ilişki var mıdır?

- Ortaokul öğretmenlerinin kolaylaştırıı okul yapısı ve akademik iyimserlik algıları, okul etkililiği algılarının anlamlı yordayıcıları mıdır?

\section{Yöntem}

Öğretmenlerin kolaylaştırıcı okul yapısı, akademik iyimserlik ve okul etkililiği algıları arasındaki ilişkilerinin ortaya çıkarılmasının amaçlandığı bu araştırmada ilişkisel tarama modeli kullanılmıştır. İki ya da daha çok sayıdaki değişken arasındaki birlikte değişimin varlığını veya derecesini belirlemeyi amaçlayan (Karasar, 2009, s. 81) ilişkisel tarama modelinde araştırmacı, bu ilişkileri bulmak ve tanımlamak için hedeflenen verilerin toplanması dışında herhangi bir yönlendirme ya da müdahale yapmaz ve bu olguları değiştirmeye çalışmadan araştırmasını yürütür (Büyüköztürk, Kılıç-Çakmak, Akgün, Karadeniz ve Demirel, 2012, s. 16-17).

\section{Evren ve Örneklem}

Araştırmanın evrenini Giresun il ve ilçelerinde bulunan tüm ortaokullarda, 2015-2016 yılında görev yapmakta olan 1768 öğretmen oluşturmaktadır. Giresun coğrafi koşullar itibariyle dağlık ve merkeze uzak bölgelerde yer alan ilçe ve okullara sahip olduğundan, Giresun ilçelerindeki okullar ve bu okullarda görev yapan öğretmen sayıları heterojen yapı göstermektedir. Bu heterojen yapının araştırmanın sonuçlarına olumsuz etki edeceği düşünüldüğünden ve evrenin tümüne de ulaşabilme imkânı olduğundan örneklem alınmayarak tüm evren araştırmaya dahil edilmiştir. 1768 veri toplama aracı öğretmenlere gönderilmiş ancak 1196 tanesi doldurularak geri gönderilmiştir. İlk adımda eksik veya hatalı doldurulan 45 veri toplama aracı, daha sonraki adımda ise kayıp ve uç değerlerin ayıklanmasından sonra 51 veri toplama aracı analizlere dâhil edilmeyerek çıkarılmış ve sonuçta araştırmanın çalışma grubunu 1100 ortaokul öğretmeni oluşturmuştur.

\section{Veri Toplama Araçları}

Okul Etkililiği Ölçeği (OEÖ): Hoy ve Ferguson (1985) tarafindan geliştirilerek, araştırmacı tarafindan Türkçeye uyarlanan OEO orijinalinde 8 maddeden oluşan; eğitim-öğretim hizmetlerinin niteliğini ölçen 1 madde, eğitim-öğretim hizmetlerinin niceliğini ölçen 1 madde, etkinliği ölçen 2 madde, uyumu ölçen 2 madde ve esnekliği ölçen 2 madde olmak üzere toplam 5 faktörlü bir ölçektir. Araştırmacı tarafindan OEÖ'ye yapılan geçerlik çalışması sonucunda KMO değerinin .83, Barlett's katsayısının 1320.924 ( $p$ <.001) olduğu belirlenmiştir. Ölçeğe uygulanan Açımlayıcı Faktör Analizi (AFA) 
sonuçlarına göre ölçek maddelerinin 3 faktörde toplandığı ancak bu maddelerden bazılarının faktör yüklerinin $(6,8)$ uygun şekilde dağılım göstermediği görülmüştür. Bu nedenle bu maddeler ölçekten çıkarılarak kalan 6 madde değerlendirmeye alınmıştr. Kalan 6 maddeye uygulanan AFA sonuçlarına göre ölçek maddelerinin Eğitim-Öğretim (1, 2), Uyum $(4,5)$ ve Esneklik $(3,7)$ olmak üzere 3 faktör altında toplandığı sonucuna varılmıştır. Tüm ölçek maddelerinin faktör yük değerlerinin .77 ve .90 arasında değiştiği, Cronbach's Alpha katsayısının .89 olduğu ve toplam varyansın \% 86 'sını açıkladığı görülmektedir. Okul yapısının etkililiği ölçeğinde kullanılmak üzere Hoy ve Sweetland (2000) tarafindan okulların bürokratik yapılarının etkililiğinin belirlenebilmesi için bir formül oluşturmuş ve formülden elde edilen puana göre bu araştırma kapsamında ortaokul öğretmenlerinin okul yapısına ilişkin algılarının \% 84 etkili (kolaylaştırıcı) şekilde işlediği sonucuna ulaşılmıştır.

Akademik lyimserlik Ölçeği (AiÖ): Hoy (2006) tarafindan geliştirilerek Sezgin ve Erdoğan (2015) tarafindan Türkçeye uyarlanan AiÖ ölçeği orijinalinde 11 maddeden oluşan; akademik öz yeterlik alt boyutunda 3 madde, güven alt boyutunda 4 madde ve akademik önem alt boyutunda 4 madde bulunan 3 faktörlü bir ölçektir. Araştırmacı tarafindan Aiö'ye yapılan geçerlik çalışması sonucunda KMO değerinin .75, Barlett's katsayısının 2199,072 $(p<.001)$ olduğu belirlenmiştir. Ölçeğe uygulanan AFA sonuçlarına göre ölçek maddelerinin 3 faktörde toplandığı ancak bu maddelerden bazılarının faktör yüklerinin (9 ve 11) uygun şekilde dağılım göstermediği görülmüştür. Bu nedenle bu maddeler ölçekten çıkarılarak kalan 9 madde değerlendirmeye alınmıştı. Kalan 9 maddeye uygulanan AFA sonuçlarına göre ölçek maddelerinin Öz Yeterlik $(1,3,7)$, Güven $(4,5,6)$ ve Akademik Vurgu $(2,8,10)$ olmak üzere 3 faktör altında toplandığı sonucuna varılmıştır. Tüm ölçek maddelerinin faktör yük değerlerinin .45 ve .79 arasında değiştiği, Cronbach's Alpha katsayısının .74 olduğu ve toplam varyansın \%60'ını açıkladığı görülmektedir.

Okul Yapısının Etkililiği Ölçeği (OYÖ): Hoy ve Sweetland (2000) tarafindan geliştirilerek Buluç (2009) tarafindan Türkçeye uyarlanan OYÖ 12 maddeden oluşan kolaylaştııcı okul yapısı alt boyutunda 6 madde $(1,3,5,6,10,12)$ ve engelleyici okul yapısın alt boyutunda 6 madde $(2,4,7,8,9,11)$ bulunan 2 faktörlü bir ölçektir. OYÖ ölçeği için KMO değerinin .89, Barlett's katsayısının $4037.83(p<.001)$ olduğu belirlenmiştir. Araştırmacı tarafindan yapılan analizler sonucu bu ölçekten madde çıkarılmasına gerek olmadığı görülmüştür. Tüm ölçek maddelerinin faktör yük değerlerinin .22 ve .66 arasında değiştiği, Cronbach's Alpha katsayısının .83 olduğu ve toplam varyansın \%51'ini açıkladığı belirlenmiştir.

Araştırmacı tarafindan ölçeklere uygulanan Doğrulayıcı Faktör Analizi (DFA) sonuçlarına ilişkin veriler Tablo 1'de yer almaktadır.

Tablo 1. Ölçeklere iliş̧kin DFA Sonuçları

\begin{tabular}{lccccccccc}
\hline Ölçekler & $\mathrm{X}^{2}$ & $\mathrm{sd}$ & $\left(\mathrm{X}^{2} / \mathrm{sd}\right)$ & $\mathrm{RMSEA}$ & $\mathrm{CFI}$ & $\mathrm{GFI}$ & AGFI & RMR & NFI \\
\hline Okul Etkililiği & 19.52 & 6 & 3.25 & 0.080 & 0.99 & 0.98 & 0.94 & 0.023 & 0.99 \\
Akademik İyimserlik & 85.48 & 24 & 3.56 & 0.086 & 0.95 & 0.95 & 0.90 & 0.035 & 0.93 \\
Okul Yapısı & 129.96 & 53 & 2.45 & 0.065 & 0.97 & 0.94 & 0.91 & 0.05 & 0.96 \\
\hline
\end{tabular}

Ölçeklere ilişkin DFA sonuçlarına ait Tablo 1 incelendiğinde OEÖ’ye ait 3 faktörlü modelin kabul edilebilir bir uyum indeksi gösterdiği ortaya koyulmuştur $\left(X^{2} / \mathrm{sd}=3.25, \mathrm{RMSEA}=0.080, \mathrm{CFI}=0.99, \mathrm{GFI}=0.98\right)$. Aï̈’ye ilişkin modelin uyum değerleri incelendiğinde ölçme modelinin kabul edilebilir bir model olduğu ve 3 faktörlü yapının iyi bir modele sahip olduğu söylenebilir $\left(X^{2} / \mathrm{sd}=3.56\right.$, RMSEA=0.086, $\left.\mathrm{CFI}=0.95, \mathrm{GFI}=0.95\right)$. OYÖ'nün 2 faktörlü yapısının DFA tarafindan doğrulanmış ve bu 2 faktörlü modelin kabul edilebilir bir uyumluluk düzeyi indeksine sahip olduğu da Tablo 2'de görülmektedir $\left(X^{2} / \mathrm{sd}=2.45, \mathrm{RMSEA}=0.065, \mathrm{CFI}=0.97, \mathrm{GFI}=0.97\right)$.

\section{Bulgular}

\section{Öğretmenlerin Okul Etkililiği, Akademik İyimserlik ve Okul Yapısı Algıları Arasındaki ilişkilere Ait Bulgular}

Öğretmenlerin okul etkililiği, akademik iyimserlik ve okul yapısı algıları arasındaki ilişkileri gösteren Tablo 2 değişkenler arasında çoğunlukla pozitif yönde, anlamlı ve orta düzeyde ilişkiler olduğu görülmektedir. Orta düzeyde en yüksek ilişkinin okul yapısının alt boyutu olan kolaylaştııcı okul yapısı ile okul etkililiği arasında olduğu $(r=.40)$; okul yapısı ile okul etkililiğinin alt boyutu olan eğitim-öğretim arasında $(r=.36)$, okul etkililiği arasında $(r=.36)$, akademik iyimserlik arasında $(r=.30)$ ve akademik iyimserliğin alt boyutu olan öz yeterlik arasında $(r=.31)$ pozitif yönlü, orta düzeyde ve anlamlı ilişkiler olduğu görülmektedir. Kolaylaştııcı okul yapısı ile okul etkililiğinin alt boyutları olan eğitim-öğretim arasında $(r=.38)$, uyum arasında $(r=.35)$ ve esneklik arasında $(r=.31)$ pozitif yönlü, orta düzeyde ve anlamlı ilişkiler olduğu belirlenmiştir. Ayrıca akademik iyimserlik ile okul etkililiği arasında $(r=.32)$ ve akademik iyimserliğin alt boyutu olan öz yeterlik ile okul etkililiği ( $r=.31)$ pozitif yönlü, orta dereceli ve anlamlı ilişkiler olduğu görülmektedir. 
Tablo 2. Öğretmenlerin Okul Etkililiği, Akademik İyimserlik ve Okul Yapısı Algıları Arasındaki ilişkiler ( $\mathrm{n}=1100)$

\begin{tabular}{|c|c|c|c|c|c|c|c|c|c|c|c|}
\hline Değişkenler & 11 & 22 & 33 & 44 & 55 & 66 & 77 & 88 & 99 & 110 & 111 \\
\hline Okul Yapısı (Toplam) & 11.00 & $.86 * *$ & $.86 * *$ & $.30 * *$ & $.31 * *$ & $.16 * *$ & $.24 * *$ & $.36 * *$ & $.36 * *$ & $.29 * *$ & $.27 * *$ \\
\hline Engelleyici Okul Yapısı & & 11.00 & $.47^{* *}$ & $.16 * *$ & $.19 * *$ & $.04 * *$ & $.14 * *$ & $.21 * *$ & $.24 * *$ & $.16 * *$ & .15 \\
\hline Kolaylaştırıcı Okul Yapısı & & & 11.00 & $.36 * *$ & $.33^{* *}$ & $.23 * *$ & $.26 * *$ & $.40 * *$ & $.38 * *$ & $.35 * *$ & $.31 * *$ \\
\hline Akademik İyim. (Toplam) & & & & 11.00 & $.74^{* *}$ & $.78 * *$ & $.70 * *$ & $.32 * *$ & $.28 * *$ & $.26 * *$ & $.29 * *$ \\
\hline Öz yeterlik & & & & & 11.00 & $.33 * *$ & $.47^{* *}$ & $.31 * *$ & $.27^{* *}$ & $.24 * *$ & $.29 * *$ \\
\hline Güven & & & & & & 11.00 & $.22 * *$ & $.15^{* *}$ & $.14^{* *}$ & $.13^{* *}$ & $.13^{* *}$ \\
\hline Akademik Vurgu & & & & & & & 11.00 & $.29 * *$ & $.24 * *$ & $.23 * *$ & $.28 * *$ \\
\hline Okul Etkililiği (Toplam) & & & & & & & & 11.00 & $.83^{* *}$ & $.86^{* *}$ & $.88^{* *}$ \\
\hline Eğitim-Öğretim & & & & & & & & & 11.00 & $.54 * *$ & $.61^{* *}$ \\
\hline Uyum & & & & & & & & & & 11.00 & $.67 * *$ \\
\hline Esneklik & & & & & & & & & & & 11.00 \\
\hline
\end{tabular}

\section{Öğretmenlerin Okul Etkililiği Algılarında Yordayıcı Olarak Okul Yapısı ve Akademik İyimserlik}

Öğretmenlerin okul etkililiği algılarının yordayıcıları olarak okul yapısı ve akademik iyimserlik algılarına ilişkin bulgular Tablo 3'te; okul etkililiği algılarının yordayıcıları olarak okul yapısının alt boyutları olan kolaylaştırıcı okul yapısı ve engelleyici okul yapısı algıları ile akademik iyimserliğin alt boyutları olan öz yeterlik, akademik vurgu ve güven algılarına ilişkin bulgular Tablo 4'te; okul etkililiğinin alt boyutu olan eğitim öğretimin yordayıcıları olarak kolaylaştırıcı okul yapısı ve engelleyici okul yapısı algıları ile öz yeterlik, akademik vurgu ve güven algılarına ilişkin bulgular Tablo 5'te, esneklik alt boyutunun yordayıcıları olarak kolaylaştırıcı okul yapısı ve engelleyici okul yapısı algıları ile öz yeterlik, akademik vurgu ve güven algılarına ilişkin bulgular Tablo 6 'da, uyum alt boyutunun yordayıcıları olarak kolaylaştırıcı okul yapısı ve engelleyici okul yapısı algıları ile öz yeterlik, akademik vurgu ve güven algılarına ilişkin bulgular Tablo 7'de verilmiştir.

Tablo 3. Okul Etkililiğinin Yordanmasına Ilişkin Çoklu Doğrusal Regresyon Analizi Sonuçları

\begin{tabular}{|c|c|c|c|c|c|}
\hline Değişken & B & Standart HataB & $\beta$ & $\mathrm{t}$ & $\mathrm{p}$ \\
\hline Sabit & 1.23 & .21 & - & 5.66 & .00 \\
\hline Akademik İyimserlik & .52 & .05 & .28 & 9.69 & .00 \\
\hline Okul Yapısı & .36 & .03 & .29 & 9.88 & .00 \\
\hline
\end{tabular}

Tablo 3 incelendiğinde öğretmenlerin okul etkililiği algılarının akademik iyimserlik ve okul yapısı algıları ile orta düzeyde ve anlamlı bir ilişki vermekte olduğu görülmektedir $(R=.58, p<.05)$. Bu yordayıcı değişkenler, okul etkililiğine ait varyansın \%22'sini açıklamakta olup standardize edilmiş regresyon katsayılarına göre, okul etkililiği üzerindeki göreli önem sıraları; okul yapısı ( $\beta=.29)$ ve akademik vurgu $(\beta=.28)$ şeklindedir. Regresyon katsayılarının anlamlılı̆ına ilişkin $t$-testi sonuçları incelendiğinde ise, okul yapısı $(t=9.88, p<.05)$ ve akademik vurgunun $(t=9.69, p<.05)$ okul etkililiği üzerinde anlamlı yordayıcılar olduğu görülmektedir.

Tablo 4. Okul Etkililiğinin Okul Yapısı ve Akademik İyimserliğin Alt Boyutlarına Göre Yordanmasına ilişkin Çoklu Doğrusal Regresyon Analizi Sonuçları

\begin{tabular}{lccccc}
\hline Değişken & $\mathrm{B}$ & Standart HataB & $\beta$ & $\mathrm{t}$ & $\mathrm{p}$ \\
\hline Sabit & 1.12 & .22 & - & 5.02 & .00 \\
Kolaylaştirıcı Okul Yapısı & .33 & .03 & .30 & 9.37 & .00 \\
Engelleyici Okul Yapısı & .00 & .03 & .00 & .25 & .80 \\
Öz Yeterlik & .19 & .05 & .12 & 3.70 & .00 \\
Güven & .03 & .03 & .03 & 1.03 & .30 \\
Akademik Vurgu & .33 & .04 & .21 & 6.90 & .00 \\
\hline$F(5-1008)=73.582 \quad p=.00$ & $\mathrm{R}=.51 \quad \mathrm{R}^{2}=.26$ & & & &
\end{tabular}

Öğretmenlerin okul etkililiği algılarının okul yapısının alt boyutları ve akademik iyimserliğin alt boyutlarına göre yordanmasına ilişkin regresyon analizi sonuçlarına ilişkin Tablo 4 incelendiğinde öğretmenlerin okul etkililiği algılarının kolaylaşttrıcı okul yapısı, engelleyici okul yapısı, öz yeterlik, akademik vurgu ve güven ile orta düzeyde ve anlamlı bir ilişki vermekte olduğu görülmektedir $(R=.51, p<.05)$. Bu yordayıcı değişkenler, okul etkililiğine ait varyansın \%26'sını 
açıklamakta olup standardize edilmiş regresyon katsayılarına göre, okul etkililiği üzerindeki göreli önem sıraları; kolaylaştrıcı okul yapısı $(\beta=.30)$, akademik vurgu $(\beta=.21)$, öz yeterlik $(\beta=.12)$, güven ( $\beta=.03)$ ve engelleyici okul yapısı $(\beta$ $=.00)$ şeklindedir. Regresyon katsayılarııın anlamlılığına ilişkin t-testi sonuçları incelendiğinde ise, kolaylaştırıcı okul yapısı ( $t=9.37, p<.05)$, akademik vurgu $(t=6.90, p<.05)$, öz yeterlik $(t=3.70, p<.05)$ ve güvenin $(t=1.03, p<.05)$ okul etkililiği üzerinde anlamlı yordayıcılar olduğu fakat engelleyici okul yapısı alt boyutunun $(t=.25, p>.05)$ anlamlı bir yordayıcı olmadığı görülmektedir.

Tablo 5. Esnekliğin Yordanmasına iliş̧kin Çoklu Doğrusal Regresyon Analizi Sonuçları

\begin{tabular}{lccccc}
\hline Değişken & $\mathrm{B}$ & Standart HataB & $\beta$ & $\mathrm{t}$ & $\mathrm{p}$ \\
\hline Sabit & 1.11 & .27 & - & 4.17 & .00 \\
Kolaylaşttrıcı Okul Yapısı & .27 & .04 & .22 & 6.43 & .00 \\
Engelleyici Okul Yapısı & -.01 & .04 & -.01 & -.38 & .70 \\
Öz Yeterlik & .21 & .06 & .11 & 3.29 & .00 \\
Güven & .01 & .03 & .01 & .52 & .60 \\
Akademik Vurgu & .39 & .05 & .22 & 6.71 & .00 \\
\hline \multicolumn{1}{c}{$F(5-1008)=46.462$} & $p=.00$ & $\mathrm{R}=.43 \quad \mathrm{R}^{2}=.18$ & & &
\end{tabular}

Öğretmenlerin okul etkililiğinin alt boyutu olan esneklik algılarının okul yapısının alt boyutları ve akademik iyimserliğin alt boyutlarına göre yordanmasına ilişkin Tablo 5 incelendiğinde öğretmenlerin esneklik algılarının kolaylaştrıcı okul yapısı, engelleyici okul yapısı, öz yeterlik, akademik vurgu ve güven ile orta düzeyde ve anlamlı bir ilişki vermekte olduğu görülmektedir $(R=.43, p<.05)$. Bu yordayıcı değişkenler, okul etkililiğine ait varyansın \%18'ini açıklamakta olup standardize edilmiş regresyon katsayılarına göre, okul etkililiği üzerindeki göreli önem sıraları; kolaylaştırıcı okul yapısı ve akademik vurgu ( $\beta=.22)$, öz yeterlik $(\beta=.11)$, güven $(\beta=.01)$ ve engelleyici okul yapısı $(\beta=-.01)$ şeklindedir. Regresyon katsayılarının anlamlılığına ilişkin $t$-testi sonuçları incelendiğinde ise, kolaylaştırıcı okul yapısı $(t=6.43$, $p<.05)$, akademik vurgu ( $t=6.71, p<.05)$ ve öz yeterliğin $(t=3.29, p<.05)$ okul etkililiğinin alt boyutu olan esneklik üzerinde anlamlı yordayıcılar olduğu fakat engelleyici okul yapısı $(t=-.38, p>.05)$ ve güvenin $(t=.52, p>.05)$ anlamlı birer yordayıcı olmadığı görülmektedir.

Tablo 6. Eğitim-Öğretimin Yordanmasına iliş̧kin Çoklu Doğrusal Regresyon Analizi Sonuçları

\begin{tabular}{|c|c|c|c|c|c|}
\hline Değişken & B & Standart HataB & $\beta$ & $\mathrm{t}$ & $p$ \\
\hline Sabit & .95 & .27 & - & 3.49 & .00 \\
\hline Kolaylaştırıcı Okul Yapısı & .35 & .04 & .27 & 8.22 & .00 \\
\hline Engelleyici Okul Yapısı & .07 & .04 & .05 & 1.82 & .06 \\
\hline Öz Yeterlik & .19 & .06 & .09 & 2.97 & .00 \\
\hline Güven & .06 & .03 & .04 & 1.65 & .09 \\
\hline Akademik Vurgu & .29 & .05 & .16 & 5.04 & .00 \\
\hline
\end{tabular}

Tablo 6'ya göre öğretmenlerin okul etkililiğinin alt boyutu olan eğitim öğretim algıları ile kolaylaştırıcı okul yapısı, engelleyici okul yapısı, öz yeterlik, akademik vurgu ve güven algıları arasında orta düzeyde ve anlamlı bir ilişki olduğu görülmektedir $(R=.47, \mathrm{p}<.05)$. Bu yordayıcı değişkenler, okul etkililiğine ait varyansın \%22'sini açıklamakta olup standardize edilmiş regresyon katsayılarına göre, okul etkililiği üzerindeki göreli önem sıraları; kolaylaştrıcı okul yapısı $(\beta=.27)$, akademik vurgu $(\beta=.16)$, öz yeterlik $(\beta=.09)$, engelleyici okul yapısı $(\beta=.05)$ ve güven $(\beta=.04)$ şeklindedir. Regresyon katsayılarının anlamlılı̆ına ilişkin $t$-testi sonuçları incelendiğinde ise, kolaylaştııcı okul yapısı $(t=8.22, p<$ $.05)$, akademik vurgu $(t=5.04, p<.05)$ ve öz yeterliğin $(t=2.97, p<.05)$ okul etkililiğinin alt boyutu olan eğitim öğretim üzerinde anlamlı yordayıcılar olduğu fakat engelleyici okul yapısı $(t=1.82, p>.05)$ ve güven $(t=1.65, p>.05)$ anlamlı birer yordayıcı olmadığı görülmektedir.

Tablo 7. Uyumun Yordanmasına İlişkin Çoklu Doğrusal Regresyon Analizi Sonuçları

\begin{tabular}{|c|c|c|c|c|c|}
\hline Değişken & B & Standart HataB & $\beta$ & $\mathrm{t}$ & $\mathrm{p}$ \\
\hline Sabit & 1.30 & .28 & - & 4.64 & .00 \\
\hline Kolaylaştırıcı Okul Yapısı & .36 & .04 & .28 & 8.32 & .00 \\
\hline Engelleyici Okul Yapısı & -.03 & .04 & -.02 & -.79 & .42 \\
\hline Öz Yeterlik & .18 & .06 & .09 & 2.82 & .00 \\
\hline Güven & .01 & .03 & .01 & .37 & .71 \\
\hline Akademik Vurgu & .31 & .06 & .17 & 5.21 & .00 \\
\hline
\end{tabular}


Öğretmenlerin okul etkililiğinin alt boyutu olan uyum algılarının kolaylaştırıcı okul yapısı, engelleyici okul yapısı, öz yeterlik, akademik vurgu ve güven değişkenlerine göre yordanmasına ilişkin Tablo 7 incelendiğinde esnekliğin kolaylaştrııı okul yapısı, engelleyici okul yapısı, öz yeterlik, akademik vurgu ve güven algıları ile orta düzeyde ve anlamlı bir ilişki olduğu görülmektedir $(R=.43, p<.05)$. Bu yordayıcı değişkenler, okul etkililiğine ait varyansın \%18' ini açıklamakta olup standardize edilmiş regresyon katsayılarına göre, okul etkililiği üzerindeki göreli önem sıraları; kolaylaştırıcı okul yapısı ( $\beta=.28)$, akademik vurgu ( $\beta=.17)$, öz yeterlik $(\beta=.09)$, güven $(\beta=.01)$ ve engelleyici okul yapısı $(\beta=-.02)$ şeklindedir. Regresyon katsayılarının anlamlılığına ilişkin t-testi sonuçları incelendiğinde ise, kolaylaştırıcı okul yapısı $(t=8.32, p<$ $.05)$, akademik vurgu $(t=5.21, p<.05)$ ve öz yeterliğin $(t=2.82, p<.05)$ okul etkililiğinin alt boyutu olan uyum üzerinde anlamlı yordayıcılar olduğu fakat engelleyici okul yapısı $(t=.42, p>.05)$ ve güvenin $(t=.71, p>.05)$ anlamlı birer yordayıcı olmadığı görülmektedir.

\section{Tartışma ve Sonuç}

Öğretmenlerin kolaylaştırııı okul yapısı, akademik iyimserlik ve okul etkililiği algıları arasındaki ilişkilerin araştırıldığı ve akademik iyimserlik algısı ile kolaylaştıııcı okul yapısı algısının okul etkililiği algıları üzerindeki yordayıcılıklarının incelendiği bu araşttrmanın bulgularına göre;

- Öğretmenlerin okul yapısı, akademik iyimserlik ve okul etkililiği düzeylerinin ilişkileri bakımından en yüksek ilişkinin okul yapısının alt boyutu olan kolaylaştıııcı okul yapısı ile okul etkililiği arasında, en düşük düzeyli ilişkinin ise okul yapısının alt boyutu olan engelleyici okul yapısı ile akademik iyimserliğin alt boyutu olan güven arasında olduğu,

- Okul yapısı ile okul etkililiğinin alt boyutu olan eğitim-öğretim arasında, okul etkililiği arasında, akademik iyimserlik arasında ve akademik iyimserliğin alt boyutu olan öz yeterlik arasında pozitif yönlü, orta düzeyde ve anlamlı ilişkiler olduğu,

- Kolaylaştırıcı okul yapısı ile okul etkililiğinin alt boyutları olan eğitim-öğretim arasında, uyum arasında ve esneklik arasında pozitif yönlü, orta düzeyde ve anlamlı ilişkiler olduğu,

- Akademik iyimserlik ile okul etkililiği arasında ve akademik iyimserliğin alt boyutu olan öz yeterlik ile okul etkililiği pozitif yönlü, orta dereceli ve anlamlı ilişkiler olduğu,

- Okul yapısı ve akademik iyimserliğin okul etkililiğinin anlamlı yordayıcıları olduğu,

- Kolaylaştırıcı okul yapısı, öz yeterlik ve akademik vurgunun okul etkililiğinin anlamlı yordayıcıları olduğu ancak; engelleyici okul yapısı ve güvenin okul etkililiğinin anlamlı yordayıcıları olmadığı,

- Ayrıca okul etkililiğinin alt boyutları olan esnekliğin, eğitim öğretimin ve uyumun ayrı ayrı yordanmasına yönelik sonuçlar incelendiğinde kolaylaştırıcı okul yapısı, öz yeterlik ve akademik vurgunun her üç boyutta da anlamlı yordayıcılar olduğu ancak; engelleyici okul yapısı ve güvenin her üç boyutta da anlamlı yordayıcılar olmadığı sonucuna ulaşılmıştir.

Bu araştırmanın yukarıda ifade edilen bulgularının ilgili literatürde daha önce yapılmış bazı araştırma sonuçları ile uyumlu olduğu görülmektedir. Yapılan bir araştırmanın sonucuna göre kolaylaştırıcı okul yapısı ile akademik iyimserlik arasında pozitif yönde ve anlamlı ilişkiler olduğu sonucuna varılmıştır (Messick, 2002). Adams (2003) çalışmasında kolaylaştııcı okul yapısının öğretmen öz yeterliğini geliştirmede önemli olduğu sonucuna ulaşırken, Rhoads (2009) kolaylaştrıcı okul yapısı ile öğretmen öz yeterliği arasında pozitif yönde ve anlamlı ilişkiler olduğu sonucuna ulaşmıştr. Tracy (2009) çalışmasında okul yapısının okul etkililiği ile ilişkili olduğunu, Anderson (2012) ise kolaylaştırıcı okul yapısı ile akademik iyimserlik arasında anlamlı ilişkiler olduğunu tespit etmiştir. Özdemir ve Kılınç (2014) etkili bürokratik okul yapısı ile öğretmenlerin akademik iyimserlik düzeyleri arasında olumlu ve anlamlı bir ilişki olduğu sonucuna ulaşmışlardır. Bu çalışmalara ek olarak yapılan bir diğer araştırmanın sonucuna göre bürokratik okul yapısı ile öğretmen öz yeterliği arasında pozitif ve anlamlı ilişkiler olduğu sonucuna ulaşılmıştı (Kılınç, Koşar, Er \& Öğdem, 2016). Bu araştırmanın yukarıda ifade edilen bulguları ilgili literatürde daha önce yapılmış bazı araştırma sonuçlarıyla ise uyumlu olmadığı görülmektedir. Örneğin Guldan (2004)'ın kolaylaştırııı bürokrasi, okul güveni ve öz yeterlik arasındaki ilişkiyi ortaya koymayı amaçladığı çalışmasının sonucuna göre kolaylaştırıcı okul yapısı ile öz yeterlik arasında anlamlı bir ilişki tespit edilememiştir.

\section{5. Öneriler}

Öğretmenlerin okul yapısı, akademik iyimserlik ve okul etkililiği algılarını etkileyebilecek başka örgütsel değişkenlerin araştırılması ile okul yapısı, akademik iyimserlik ve okul etkililiği ile ilgili daha ayrıntılı bilgilere ulaşılmasını sağlanabilir. Sadece öğretmenlerin görüşleri alınmayıp akademik iyimserlik bağlamında düşünüldüğünde öğrenci ve velinin, okul 
yapısı düşünüldüğünde okul yöneticilerinin ve okul etkililiği düşünüldüğünde ise eğitimin çok daha geniş kapsamlı paydaşlarııın okul sistemine dahil olduğu göz önünde bulundurularak farklı katılımcı gruplarının görüşleri alınarak daha geniş verilerin elde edilebileceği çalışmalar yapılabilir. Okul etkililiğin yordanmasında akademik iyimserliğin alt boyutu olan güven değişkeni anlamlı bir yordayıcı olarak tespit edilmemiş olması göz önünde bulundurularak öğretmenlerin güven algılarına ilişkin çeşitli araştırmalar yapılabilir. Öğretmenlerin algılarına göre kolaylaştırıcı okul yapısının okul etkililiğini yordayıcılıkta anlamlı bir değişken olduğu sonucuna göre okulların bürokratik yapılarının kolaylaştrıcı yönde geliştirilmesi yönünde gerek okul içi yönetimden gerekse de üst yönetimden destek alınabilir.

\section{Kaynakça}

Adams, C. M. \& Forsyth, P. B. (2013). Revisiting the trust effect in urban elementary schools. The Elementary School Journal, 114(1), 1-21.

Anderson, K. (2012). Examining relationships between enabling structures, academic optimism and student achievement. Doctoral Dissertation. The Auburn University. Retrieved from ProQuest Dissertations and Thesis database.

Ayık, A. \& Ada, Ş. (2009). iliköğretim okullarında oluşturulan okul kültürü ile okulların etkililiği arasındaki ilişki. Gaziantep Üniversitesi Sosyal Bilimler Dergisi, (8)2, 429- 446.

Beard. K. S., Hoy, W. K. \& Woolfolk-Hoy, A. (2010). Academic optimism of individual teachers: Confirming a new construct. Teaching and Teacher Education, 26, 1136-1144.

Bevel, R. K. (2010). The effects of academic optimism on student academic achievement in Alabama. Doctoral dissertation, Alabama University. Retrieved from ProQuest Dissertations and Thesis database.

Boonen, T., Pinxten, M., Damme, J. V. \& Onghena, P. (2014). Should schools be optimistic? An investigation of the association between academic optimism of schools and student achievement in primary education. Educational Research and Evaluation, (20)1, 3-24.

Brice, R. W. (1992). Principals in Saskatchewan rural schools: Their leadership behaviors and school effectiveness. Doctoral dissertation, University of San Diego. Retrieved from ProQuest Dissertations and Thesis database.

Buluç, B. (2009). İlköğretim okullarında bürokratik okul yapısı ile okul müdürlerinin liderlik stilleri arasındaki ilişki. Eğitim ve Bilim, 34(152), 71-86.

Buzzi, M. J. (1990). The relationship of school effectiveness to selected dimensions of principals' instructional leadership in elementary schools in the state of Connecticut. Doctoral dissertation, University of Bridgeport. Retrieved from ProQuest Dissertations and Thesis database.

Büyüköztürk, Ş., Çakmak-Kılıç, E., Akgün, Ö. E., Karadeniz, Ş. ve Demirel, F. (2012). Bilimsel araştırma yöntemleri. Ankara: Pegem.

Cerit, Y. (2012). Okulun bürokratik yapısı ile sınıf öğretmenlerinin profesyonel davranışları arasındaki ilişki. Kuram ve Uygulamada Eğitim Yönetimi, 18(4), 497-521.

Chang, H. (2011). A study of the relationships between distributed leadership, teacher academic optimism and student achievement in taiwanese elementary schools. School Leadership and Management, 31(5), 491-515.

Cooper, J. D. (2010). Collective efficacy, organizational citizenship behavior, and school effectiveness in alabama public high schools. Doctoral dissertation, The University of Alabama. Retrieved from ProQuest Dissertations and Thesis database.

Çağlar, Ç. (2013). Okulların akademik iyimserlik düzeylerinin öğretmenlerin örgütsel bağllı̆̆ı üzerindeki etkisi. Mersin Üniversitesi Eğitim Fakültesi Dergisi, 9(1), 260-273.

Çağlar, Ç. (2014). Okulların akademik iyimserlik düzeyleri ile değişime açıklık düzeyleri arasındaki ilişki. Kuramsal Eğitimbilim Dergisi, 7(1), 94-113.

Çoban, D. \& Demirtaş, H. (2011). Okulların akademik iyimserlik düzeyi ile öğretmenlerin örgütsel bağlılı̆ı arasındaki ilişki. Kuram ve Uygulamada Eğitim Yönetimi, 17(3), 317-348.

Demirtaş, Z., Özdemir, T. Y. \& Küçük, Ö. (2016). Okulların bürokratik yapısı, örgütsel sessizlik ve örgütsel sinizm arasındaki ilişki. Kuram ve Uygulamada Eğitim Yönetimi, 22(2), 193-216.

Dodson, C. K. (2005). The relationship between school effectiveness and teachers' job satisfaction in north Mississippi schools. Doctoral dissertation, Mississippi University, Oxford. Retrieved from ProQuest Dissertations and Thesis database.

Dorman, G., Lipsitz, J. \& Verner, P. (1985). Improving schools for young adolescents. Educational Leadership, 42(6), 44-49.

Edmonds. R. R. (1979). Effective schools for the urban poor. Educational Leadership, 37(1), 15- 27.

Elmore, R. F. (1992). Why restructuring alone won't improve teaching. Educational Leadership, 49(7), 44-48.

Fahy, P., Wu, H. \& Hoy, W. K. (2010). Individual academic optimism of secondary teachers: A new concept and its measure. Analyzing School Contexts, 209-227.

Fouts, J. (2002). The power of early success: A longitudinal study of student performance on the Washington assessment of student learning, 1998-2001. Research Report. Retrieved from https://archive.org/details/ERIC_ED479541

Gökçe, F. \& Kahraman, P. B. (2010). Etkili okulun bileşenleri. Uludağ Üniversitesi Eğitim Fakültesi Dergisi 23(1), 173-206.

Guldan, E.A. (2004). Enabling bureaucracy, faculty trust, and collective efficacy in selected catholic elementary schools. Doctoral Dissertation. St. John's University. Retrieved from ProQuest Dissertations and Thesis database.

Hoy, W. K. \& Hannum, J. (1997). Middle school climate: An empirical assessment of organizational health and student achievement. Educational Administration Quarterly, 33, 290-311.

Hoy, W. K. \& Tschannen-Moran, M. (1999). Five faces of trust: an empirical confirmation in urban elementary schools. Journal of School Leadship. 8, 336-359.

| Kastamonu Eğitim Dergisi, 27(4), 2019 | 
Hoy, W. \& Sweetland, S. (2000). School bureaucracies that work: Enabling, not coercive. Journal of School Leadership, 10(6), 525-541.

Hoy, W. K., \& Sweetland, S. R. (2001). Designing better schools: The meaning and measure of enabling school structures. Educational Administration Quarterly. 3(3), 296-321.

Hoy, W. K., Tarter, C. J. \& Hoy, A. W. (2006). Academic optimism of schools: a force for student achievement. American Educational Research Journal, 43(3), 425-446.

İkbal, Y. (2016). The relationshıp between distributed leadership, enabling school structure, teacher collaboration, academic optimism and student achievement: A school effectiveness Model. Doktora Tezi, Orta Doğu Teknik Üniversitesi, Ankara. https://tez.yok.gov.tr sayfasından erişilmiştir.

Jacob, J. (2003). A study of school climate and enabling bureaucracy in select new york city public elementary schools. Doctoral Dissertation, St. John's University. Retrieved from ProQuest Dissertations and Thesis database.

Karasar, N. (2009). Bilimsel araştırma yöntemi. Ankara: Nobel.

Kılınç, A. Ç. (2013). The relationship between ındividual teacher academic optimism and school climate. International Online Journal of Educational Sciences, 5(3), 621-634.

Kılınç, A. Ç., Koşar, S., Er, E. \& Öğdem, Z. (2016). The relationship between bureaucratic school structures and teacher self-efficacy. McGill Journal Of Education, 51(1), 615-634.

Lassiter, E. L. (1994). An assessment of the relationshıp between student perceptions of school effectiveness and student achievement and social adjustment in zoned comprehensive public high schools. Doctoral dissertation, Morgan State Unıversity. Retrieved from ProQuest Dissertations and Thesis database.

Malloy, J. P. (2012). Affects of distributed leadership on teachers'academic optimism and student achievement. Doctoral dissertation, University of Toronto.

Marshall, R. P. (2013). Teacher flow and its relationship to school mindfulness and enabling school structure. Doctoral dissertation, Alabama University. Retrieved from ProQuest Dissertations and Thesis database.

Mcguigan, L. (2005). The role of enabling bureaucracy and academic optimism in academic achievement growth. Doctoral Dissertation. The Ohio State University. Retrieved from ProQuest Dissertations and Thesis database.

Messick, P. P. (2012). Examining relationships among enabling school structures, academic optimism and organizational citizenship behaviors. Doctoral Dissertation. Auburn University. Retrieved from ProQuest Dissertations and Thesis database.

Özdemir, S. \& Kılınç, A. Ç. (2014). Bürokratik okul yapısı ile öğretmenlerin akademik iyimserlik düzeyleri arasındaki ilişki. Eğitimde Kuram ve Uygulama, 10(1), 1-23.

Rhoads, D. H. (2009). Enabling Structure And Collective Efficacy: A Study Of Teacher Perceptions In Elementary Divisions Of American Schools In Mexıco. Doctoral Dissertation. Seton Hall University. Retrieved from ProQuest Dissertations and Thesis database.

Rutledge II, R. D. (2010). The effects of transformational leadership on academic optimism within elementary schools. Doctoral dissertation, Alabama University. Retrieved from ProQuest Dissertations and Thesis database.

Sezgin, F. \& Erdoğan, O. (2015). Academic optimism, hope and zest for work as predictors of teacher self-efficacy and perceived success. Educational Sciences: Theory \& Practice, 15(1), 7-19.

Sinden J. E., Hoy, W, K. \& Sweetland, S.R. (2004). An analysis of enabling school structure: Theoretical, empirical, and research considerations. Journal of Educational Administration, 42(4), 462-478.

Smith, P.A. \& Hoy, W.K. (2007). Academic optimism and student achievement in urban elementary schools, Journal of Educational Administration, 45(5), 556-568.

Tarter, C J. \& Hoy, W. K. (2004). A systems approach to quality in elementary schools. Journal of Educational Administration, $42(5), 539-554$.

Tracy, J. C. (2006). Mindfulness and enabling structure as predictors of school effectiveness. Doctoral Dissertation. St. John's University. Retrieved from ProQuest Dissertations and Thesis database.

Turner, M. A. (2002). The perception of school effectiveness and school improvement by teachers in low-performing schools after state team intervention. Doctoral dissertation, University of North Carolina. Retrieved from ProQuest Dissertations and Thesis database.

Uzun, B. (2014). Sınıf öğretmenlerinin sahip olduğu değerler ile akademik iyimserlik düzeyleri arasındaki ilişki. Yüksek Lisans Tezi, Gazi Üniversitesi, Eğitim Bilimleri Enstitüsü, Ankara. https://tez.yok.gov.tr sayfasından erişilmiştir.

Watts, D. M. (2009). Enabling school structure, mindfulness, and teacher empowerment: Test of a theory. Doctoral Dissertation. The University of Alabama. Retrieved from ProQuest Dissertations and Thesis database.

Wu, H. (2012). Collective responsibility, academic optimism, and student achievement in Taiwan elementary schools. Doctoral dissertation. Graduate School of The Ohio State University, Ohio. Retrieved from ProQuest Dissertations and Thesis database.

Wu, J. H., Hoy, W. K. \& Tarter, C. J. (2013). Enabling school structure, collective responsibility, and a culture of academic optimism. Journal of Educational Administration, 51(2), 176-193.

Yalçın, S. (2013). Illköğretim okulu öğretmenlerinin mesleki tükenmişlik düzeyleri ile stres, psikolojik dayanıklılk ve akademik iyimserlik arasındaki ilişki. Yüksek Lisans Tezi, Gazi Üniversitesi, Eğitim Bilimleri Enstitüsü, Ankara. https://tez.yok.gov.tr sayfasından erişilmiştir.

Yılmaz, E. \& Kurşun, A. T. (2015). Okul kültürü ile akademik iyimserlik arasındaki ilişki. Mehmet Akif Ersoy Üniversitesi Eğitim Fakültesi Dergisi, 35, 46-69.

Zigarelli, M. A. (1996). An empirical test of conculisions from effective schools research. The Journal of Educational Research, 90(2), 103-110.

| Kastamonu Eğitim Dergisi, 27(4), 2019| 